\title{
Feeding of two species of Scydmaeninae "hole scrapers", Cephennium majus and C. ruthenum (Coleoptera: Staphylinidae), on oribatid mites
}

\author{
PAWEk JAŁOSZYŃSKI ${ }^{1}$ and ZIEMOWIT OLSZANOWSKI ${ }^{2}$ \\ ${ }^{1}$ Museum of Natural History, University of Wrocław, Sienkiewicza 21, 50-335 Wrocław, Poland; \\ e-mail: scydmaenus@yahoo.com \\ ${ }^{2}$ Department of Animal Taxonomy and Ecology, A. Mickiewicz University, Umultowska 89, 61-614 Poznań, Poland; \\ e-mail: olszanow@amu.edu.pl
}

Key words. Coleoptera, Staphylinidae, Scydmaeninae, Cephenniini, Cephennium, Palaearctic, prey preferences, feeding behaviour, Oribatida, Mesostigmata

\begin{abstract}
Prey preferences and feeding-related behaviour of two Central European species of Scydmaeninae, Cephennium majus and Cephennium ruthenum, were studied under laboratory conditions. These beetles capture mites by using unique premental suckers and then penetrate the prey's cuticle by slowly scraping a hole with their short mandibles. A mechanism for interlocking the sides of beetle's labrum with closed mandibles was discovered, confirming that the predator's mouthparts can be tightly sealed around the penetration site, which enables them to inject digestive juices and ingest liquefied tissues of the prey through a tiny hole. The feeding behaviour of Cephennium can be divided into three phases: (i) attack and stabilization of the attachment site (4-5 min); (ii) penetration of the mite's cuticle (ca. $40 \mathrm{~min}$ ); and (iii) feeding (several hours). Results of prey choice experiments using over 1200 identified mites belonging to 23 families of Oribatida ( 55 species) and 6 families of Mesostigmata ( 9 species) demonstrated that C. majus feeds mostly on members of the Oribatida: Phthiracaridae $(72.07 \%$ of offered phthiracarids, $26.7 \%$ of eaten oribatids), Ceratozetidae (100\% and $24.7 \%$, respectively), Achipteriidae $(95.59 \%$ and $21.7 \%)$ and Liacaridae $(61.97 \%$ and $14.7 \%)$; C. ruthenum fed mostly on Phthiracaridae (48.68\% and $41.6 \%)$, Achipteriidae $(37.29 \%$ and $24.7 \%)$ and Ceratozetidae $(82.35 \%$ and $15.7 \%)$. The entire feeding behaviour from attack to completion of feeding in C. majus took $2.00-10.37 \mathrm{~h}$ when eating oribatids ranging in body length from 0.34 to $0.70 \mathrm{~mm}$. Interestingly, it took much longer for $C$. majus to kill ptyctimous Phthiracarus, body length $0.39-0.45 \mathrm{~mm}$, than any non-ptyctimous oribatids, including the much larger (0.64-0.70 mm) Chamobates subglobulus. The two species of Cephennium differed greatly in their preference for eating Liacaridae due to their large size, which was acceptable for the larger $C$. majus, but at the edge of acceptability for the smaller $C$. ruthenum. Comparative analysis of mites eaten by all the studied species of Scydmaeninae resulted in a preliminary identification of morphological types of Oribatida acceptable and non-acceptable for ant-like stone beetles. The most readily accepted oribatids are typically subglobose, with a rigid cuticle, smooth or only shallowly and finely microreticulate surface of the idiosoma, covered with sparse setae or nearly asetose and with short or moderately long legs. In contrast, rejected mites have one or a combination of the following characters: body flattened, not subglobose; the cuticle relatively soft; idiosoma deeply sculptured or coarsely reticulate; legs long and spiny; the body covered with a protective crust of soil particles. Crotonioidea, Carabodidae, Damaeidae and Hermanniellidae seem to be particularly well-protected against scydmaenine predators.
\end{abstract}

\section{INTRODUCTION}

Recent results of Jałoszyński (2012a,b), Jałoszyński \& Kilian (2012) and Jałoszyński \& Olszanowski (2013, 2015) demonstrate that the feeding preferences of Scydmaeninae pose a complex research problem and cannot be summarized by a simple statement that ant-like stone beetles are predators of armoured mites. Observations under laboratory conditions revealed different prey preferences and feeding-related behaviour in the species of Scydmaeninae previously studied. It became clear that "feeding on Oribatida" in fact means marked preferences for particular morphological forms or particular families of armoured mites. Diverse morphological and behavioural adaptations of Oribatida to avoid predation are matched by a broad spectrum of methods that scydmaenines use to breach a prey's defences. By acquiring unique adaptations during the long process of evolution, scydmaenines have gained access to an enormously rich source of food in the highly competitive environment of the forest floor.

The Scydmaeninae are minute beetles (often less than $2 \mathrm{~mm}$ in length) that inhabit mainly microhabitats associated with leaf litter and rotten wood in forests (Jałoszyński, 2016). Their biology makes it nearly impossible to study their behaviour in nature, as these beetles typically avoid light, move rapidly, remain hidden within the substrate they inhabit and their known or presumed prey is also of 
microscopic size. Occasionally, however, a scydmaenine beetle carrying a mite using its mouthparts is seen when a sample of sifted leaf litter is examined in a laboratory. Such observations were made by the first author many times, and similar observations might have been the source of the notion expressed already over a hundred years ago that Scydmaeninae feed on armoured oribatid mites (Reitter, 1909). Since then, scarce but increasingly detailed observations under laboratory conditions confirmed this view (Schuster, 1966a, b; Schmid, 1988; Molleman \& Walter, 2001; Jałoszyński \& Olszanowski, 2013, 2015). However, some Scydmaeninae will eat or even prefer soft-bodied mites and springtails (Leleup, 1968; O'Keefe \& Monteith, 2001; Jałoszyński, 2012a; Jałoszyński \& Kilian, 2012), scavenge on dead arthropods (Molleman \& Walter, 2001; Jałoszyński, 2012b) and in the peculiar case of the first-instar larvae of Palaeostigus Newton, the only source of food is the secretion deposited by a female together with her eggs (De Marzo, 1983). As the biology of about 5,000 currently known species of Scydmaeninae (Newton \& Franz, 1998; Grebennikov \& Newton, 2009; Jałoszyński, 2016) is still poorly known, the current picture of their feeding preferences, techniques and adaptations is without doubt far from complete.

Previous studies of interactions between scydmaenines and their mite prey focused mostly on species that use the "cutting technique" for breaching the defence systems of Oribatida and, to a lesser extent, the mesostigmatan Uropodina. Molleman \& Walter (2001) describe the damage caused by the feeding of Scydmaeninae on oribatid and uropodine mites; subsequent studies of Jałoszyński \& Olszanowski $(2013,2015)$ provide details of the attack techniques used by Euconnus pubicollis (Müller \& Kunze) and Scydmaenus rufus Müller \& Kunze, Central European species of the Glandulariini (= Cyrtoscydmini) and Scydmaenini, respectively. The prey preferences of these two species are remarkably different. Euconnus predominantly feeds on ptyctimous Phthiracaridae, and therefore its technique of killing the prey is focused on opening an "encapsulated" mite that has its fragile body parts protected under the closed shield of the prodorsum. Scydmaenus rufus, a species that inhabits environments where ptyctimous mites are rare, feeds mainly on Scheloribatidae and Oppiidae, and it focuses on damaging the gnathosoma, and in the case of long-legged oppiids, cuts off some of the prey's legs before killing the mite. Also the initial phase of attack is different in these scydmaenines. Euconnus uses a unique technique of lifting the mite using a droplet of adhesive liquid produced by its mouthparts, while Scydmaenus solves the same problem by gripping its prey with its mandibles.

Not all scydmaenines use the cutting technique to kill their prey. Species of the large and morphologically uniform tribe Cephenniini have evolved morphological adaptations that make them capable of penetrating the mite's cuticle by "drilling" (actually scraping) a tiny hole. Schuster $(1966 a, b)$ was the first author to describe this phenomenon. He observed adults and larvae of Cephennium Müller \& Kunze patiently using their relatively short and blunt mandibles to scrape the cuticle of a captured oribatid mite, which eventually results in the penetration of the integument of the mite (Schuster, 1966b). This was called the "Lochschabetechnik" ("hole scraping technique") by Schmid (1988), who provides more detailed observations and reports that Cephennium uses paired labial suckers to capture and hold oribatid mites. Once the prey is immobilized on the suckers, the mandibles slowly grind a small hole through the prey's cuticle, a process that can take several hours. Jałoszyński \& Beutel (2012) describe the functional morphology of the specialized mouthparts of Cephenniini and discuss possible evolutionary pathways of this peculiar adaptation. The highly modified labium of the adults of Cephenniini bears four or six suckers on the prementum. A histological examination of the head of adults of Cephennium and Cephennodes Reitter and larvae of Cephennium has shed new light on the way they hold their prey, which is based on contractions and relaxations of the labial muscles that are attached to an integrated internal scaffold in the labium and hypopharynx, which changes the shape of the anterior surface of the prementum. The paired circular or oval suckers of Cephenniini have a complex internal structure and are not known in any other beetles. They play a major role in capturing and holding a mite long enough for the mandibles to scrape through the cuticle. When this is accomplished, digestive juices are injected into the prey and the liquefied soft tissues are ingested. Abandoned empty mite shells show characteristic feeding damage in the form of a small hole in the idiosoma, while all other body parts remain intact (Jałoszyński \& Beutel, 2012). In contrast, Glandulariini and Scydmaenini that feed on oribatids leave empty shells bearing obvious damage within the gnathosoma, and often also the anal and/or genital plates have been removed (Jałoszyński \& Olszanowski, 2013, 2015).

Although the hole scraping technique of Cephenniini has been known for over a half century, actual prey preferences of the species that use this method have not been studied. In the present study we selected two Central European species of Cephennium to analyse the feeding preferences and hunting behaviour of scydmaenines that breach the prey's defences by "drilling" holes in their cuticles. In earlier experiments (Jałoszyński \& Beutel, 2012) ptyctimous oribatids were indicated as the possible preferred prey, but prey preference tests were not carried out.

\section{MATERIALS AND METHODS}

\section{Material}

Adults of Cephennium majus Reitter, 1882 and Cephennium ruthenum ruthenum Machulka, 1925 (Scydmaeninae: Cephenniitae: Cephenniini) were collected near Baligród and Zwierzyń, SE Poland, on 23.-24.vi.2015, by sifting leaf litter in deciduous forests. These are externally very similar beetles; Cephennium majus has larger adults than C. ruthenum (body length of 20 drymounted specimens ranged from $1.29-1.48 \mathrm{~mm}$ for $C$. majus and $0.98-1.12 \mathrm{~mm}$ for $C$. ruthenum). The beetles were manually picked from the sifted samples and transferred to the laboratory in small plastic containers with a small amount of soil. The sifted substrate collected in Baligród and Zwierzyń was pooled and also transferred to the laboratory, from which mites were later 
extracted. As described previously (Jałoszyński \& Olszanowski, $2013,2015)$, the potential prey was selected from a broad variety of mites that emerged onto the surface of the sifted substrate. The substrate samples were placed in three closed plastic containers $(30 \times 20 \times 15 \mathrm{~cm})$ and several pieces of white $60 \mathrm{~g} / \mathrm{m}^{2}$ printing paper, each ca. $8 \times 5 \mathrm{~cm}$, were placed on the surface of the samples. Acari that gathered on both sides of these "traps" were collected every 5 days during the study and offered as potential prey to each species of Cephennium. In prey choice experiments the mites were collected by "sweeping" the surface of the paper traps with a brush over a Petri dish.

\section{Determinations}

Living beetles were identified by the first author. No attempt was made to determine the sex of the beetles, and therefore mixed groups were used. The mites, including empty shells with feeding damage, were preserved in $75 \%$ ethanol and identified by the second author after clearing in lactic acid.

\section{Prey choice experiments}

Three study groups were established (duration of experiments in parentheses), each comprising ten individuals:

1. Cephennium majus (01.-30.vii.2015)

2. Cephennium majus (01.-30.vii.2015)

3. Cephennium ruthenum (01.-30.vii.2015)

Plastic vented Petri dishes (diameter $35 \mathrm{~mm}$, height $10 \mathrm{~mm}$; Nalgene Nunc Int., Rochester, USA) half-filled with plaster of Paris were used as observation arenas and were preconditioned as described previously (Jałoszyński, 2012a,b; Jałoszyński \& Olszanowski, 2013, 2015) by filling them with pressed and moist substrate (deciduous leaf litter sifted through $3 \mathrm{~mm}$ diam. mesh) for $24 \mathrm{~h}$. This substrate was removed and each group of beetles was placed in a separate empty arena. The arenas were kept in the dark (except during observations and other manipulations, which were made under a dim light) at $22-24^{\circ} \mathrm{C}$. The plaster was moistened every second day with 3-4 droplets of distilled water. A mixture of ca. 50-100 mites were added to each group every 5 days and every day dead mites were collected and stored in ethanol for identification. Eaten mites were distinguished from those that died of other causes by the characteristic feeding damage (described and illustrated by Jałoszyński \& Beutel, 2012). Every 5 days all the living mites were collected and placed in ethanol and replaced with a fresh batch of potential prey. Observations were made every day for about one hour, usually in the morning, for 30 days. This setup was adopted based on our previous studies (Jałoszyński \& Olszanowski, 2013, 2015), in which this size of arena and other conditions proved most useful for making observations.

\section{Feeding experiments}

Details of the attack and behaviour of beetles were recorded during the prey preference experiments. Because of the long period of feeding, the initial phases of attack and feeding (typically the first $1 \mathrm{~h}$ ) were observed more than 50 times, whereas the entire process from the attack to the abandonment of an empty mite "shell" (about $8-9$ h) was only recorded on three occasions. The three complete observations were made when $0.5-0.6 \mathrm{~mm}$ long specimens of Phthiracarus spp. were the prey. The relationship between prey length and feeding time was studied only for $C$. majus, in separate experiments with four oribatid species as prey: Chamobates cuspidatus, Phthiracarus sp., Ceratozetes mediocris and Chamobates subglobulus (listed from the smallest to largest in terms of body length). These species of mites were selected in preliminary experiments as representing a relatively broad range of body lengths, but at the same time were small enough for the whole feeding process to be completed within less than 10 h. There were 11-15 replicates of this experiment for each mite species (11 beetles were fed with Ch. cuspidatus, 14 beetles with Phthiracarus sp., 13 with C. mediocris and 15 with Ch. subglobu$l u s)$. Beetles were kept without prey for $24 \mathrm{~h}$ and then placed individually in an empty and moistened $22 \mathrm{~mm}$-wide, 10 -mm high arena (clear polystyrene containers for cosmetics purchased at a local store) half-filled with plaster of Paris and preconditioned as described above. After $30 \mathrm{~min}$ a single mite was placed in the middle of the arena and observed under a stereoscopic microscope. All beetles were observed for the entire feeding process, from attacking the mite to abandonment of the empty mite shell. Observations were carried out continuously until beetles attacked the mite, after which each arena was inspected every half an hour.

\section{Scanning electron microscopy (SEM)}

Specimens of C. majus were studied after a brief cleaning in a warm $10 \%$ solution of $\mathrm{KOH}$, thorough washing in distilled water, dehydration in absolute ethanol, drying in air and mounting on SEM stubs with carbon tabs. Mites were dried directly from ethanol-stored samples and not cleaned in alkali. Beetles were killed while feeding and preserved by pouring nearly boiling $75 \%$ ethanol onto the arena. In most cases the predator and its prey did not separate and the post-mortem position of the mouthparts (holding the mite via attachment to the labial suckers) was preserved. Such specimens were stored in ethanol, briefly dried on a piece of a blotting paper and glued onto a mounting card in such a way that the mite in their mouthparts was above the card and not in contact with the glue. Entire mounting cards were placed on SEM stubs with carbon tabs. All specimens were sputter-coated with gold (High Vacuum Coater Leica EM ACE600) and examined using a Helios Nanolab 450HP scanning electron microscope (FEI, Hillsboro, USA).

\section{Light photography and image processing}

Photographs of feeding beetles were taken using a Panasonic DMC-FZ150 digital camera with a Raynox M-250 macro lens. Final image adjustments and labelling were done in Corel PhotoPaint.

\section{Measurements}

The length of the Ptyctima mites is the length of the notogaster, measured in lateral view. Non-ptyctimous mites were measured in dorsal view, from the anterior margin of the capitulum to the posterior margin of the idiosoma. Unidentifiable juvenile forms and a few specimens of Mesostigmata used in the experiments were not measured or included in the calculations. Some specimens that were partly damaged during identification were also not measured.

\section{Plots and statistics}

The data were plotted using SigmaPlot 2004 v. 9.0 (Systat Software, USA). Differences in median body lengths of eaten and non-eaten prey were assessed using the Wilcoxon-Mann-Whitney two-sample rank-sum test in Statistica 12 (StatSoft, Tulsa, USA).

\section{Terminology}

Following Jałoszyński \& Olszanowski $(2013,2015)$, "accepted prey" are the mites that were found dead and showing feeding damage $24 \mathrm{~h}$ after being placed in the arenas with beetles. "Rejected prey" were mites still alive 5 days after being placed in Petri dishes with beetles. The "access time" refers to the time from attack to the onset of rapid movements of the legs of the captured prey, which is taken as the moment of piercing through the mite's cuticle by the beetle. The "feeding time" is the time from attack to abandonment of the empty shell of the mite minus the access time. 


\section{Source of errors}

Potential sources of errors included the following factors: an experimental setup that may not reflect natural conditions; different numbers of individuals of each mite species collected from the substrate and presented to beetles that created a bias potentially resulting in overestimating the preferences for the most numerous species of prey and underestimating the preferences for the less numerous species of mites; the method adopted for collecting mites that created a bias towards those taxa that readily gathered on and under the "paper traps" as opposed to those that remained hidden in the substrate and avoided the traps. A relevant discussion of each of these factors can be found in a previously published study (Jałoszyński \& Olszanowski, 2013).

\section{RESULTS}

\section{Contact structures of Cephennium}

As the details of the mouthparts of Cephenniini, including Cephennium, are well studied (Jałoszyński \& Beutel, 2012), only intact (i.e., not disarticulated) structures were examined during the present study of $C$. majus and C. ruthenum, in order to confirm similarities with hitherto known details. Only the mouthparts of $C$. majus are illustrated (Figs 1 and 2); those of $C$. ruthenum are similar. Mouthparts of $C$. majus are subprognathous; the labrum (Figs $1-2 ; 1 b$ ) is transverse and bears a membranous anterior marginal velum (Figs 1 and 2; vel), the ventral surface of the labrum (epipharynx) is largely membranous. The mandibles (Figs 1-2; md) are short and with narrow apical portions strongly bent mesally, the apices are relatively blunt, each with a tiny subapical tubercle. Dorsally, each mandible has a small protuberance demarcated anteriorly by a notch (Figs 1-2; adn); when the mandibles are closed, lateral portions of the labrum fit tightly into this notch and interlock with the mandibles. The lacinia (Figs 1-2; lac) and galea (Figs 1-2; gal) have long apical rows of setae. The labium has a particularly well-developed, broad and movable prementum with a row of setae along the anterior premental margin (Figs 1-2; apm), between broadly separated and minute labial palps (Figs 1-2; lp). The anterodorsal surface of the prementum bears two pairs of labial suckers (Figs 1-2; 1s) separated in the middle by an elongate membranous area. The lateral lobes of the hypopharynx (Figs 1-2; 1lh) are membranous.

\section{Feeding behaviour}

Because feeding is a very long process, we only recorded three continuous observations (from offering a single mite to $C$. majus to abandonment of an empty mite shell by the beetle and all with Phthiracarus ptyctimous mites as prey), whereas initial phases of the attack and scraping a hole in the prey's cuticle (i.e., the processes that typically take place during the first $60 \mathrm{~min}$ ) were observed over 50 times. Incomplete observations of the late phases of feeding up to abandonment of an empty mite shell were recorded more than 20 times. No differences in the behaviour of the beetles or in details of the attack and feeding process were recorded for ptyctimous and non-ptyctimous mites; the description presented below is based on the three complete observations.
Phase I: attack and stabilization of the attachment site (about 4-5 min)

The first contact a beetle had with its prey was with the apices of its maxillary palps, which was immediately followed by a rapid thrust forward to establish close contact between the mite and the beetle's prementum. The mite was immediately lifted using only the beetle's mouthparts (Figs $3,4)$. Ptyctimous mites often adopted an encapsulated posture when touched by predators, i.e., with the prodorsum closed and all the legs retracted underneath; in some cases this behaviour was incomplete and frequently the encapsulation relaxed after 1-2 min (Fig. 3). Non-ptyctimous mites (Fig. 4) made chaotic leg movements when attacked and lifted; also ptyctimous mites chaotically moved their legs after opening the prodorsum. The adhesion between the beetle's mouthparts and the mite was so strong that when several beetles were killed by pouring nearly boiling $75 \%$ ethanol into the arena shortly after an attack, the attachment was maintained (Figs 8-9). Within the first 1-5 min the captured mite was usually manipulated, mainly by rotating it using the protarsi (Figs 3-4) and frequent changing or adjusting the attachment site. Some beetles did not change the initial site of attachment throughout the entire feeding process, while others changed the site several times. The manipulations took place without detaching the prey; mouthparts of beetles appeared to slide over the surface of the mite's cuticle when the attachment site was changed. When an apparently suitable site was chosen, both mandibles started rhythmically spreading and closing. This phase typically took place in a stable position, with the beetle standing on its hind and middle legs, the prey lifted above the ground and occasionally the fore tarsi and tibial apices touching the mite. The attachment site was predominantly situated dorsolaterally and posteriorly on the prey; only in small fraction of the abandoned mite shells was the feeding damage found on the midline of the prey's dorsum, either anteriorly or posteriorly; in only two mites (out of nearly 400 studied) the feeding damage was found on the lateroventral surface of mites (Achipteria coleoptrata eaten by $C$. ruthenum).

In prey choice experiments, when ten beetles were present in the same arena, several cases of nearly simultaneous attacks by two individuals on the same mite were observed (Fig. 5). The two beetles engaged in a long struggle, pulling the captured prey in opposite directions for about 20-80 min, until one of them released its grip and walked away; the winner killed and ate the prey. Three times an apparent attack by C. majus on another beetle was observed; and each time the attacked beetle was feeding on a mite (Fig. 6). Such attacks were carried out by using the labial suckers to establish a connection between the mouthparts of the attacker and the elytra of the attacked Cephennium. Even when lifted and dragged around, the attacked beetles did not abandon their prey. In two cases the attacker gave up after 15-20 min; in the third case (documented in Fig. 6) the struggle took place for over $3 \mathrm{~h}$ before the attack was terminated and both beetles walked away. The surface of the elytra of the attacked beetles was examined, but no damage was found. 

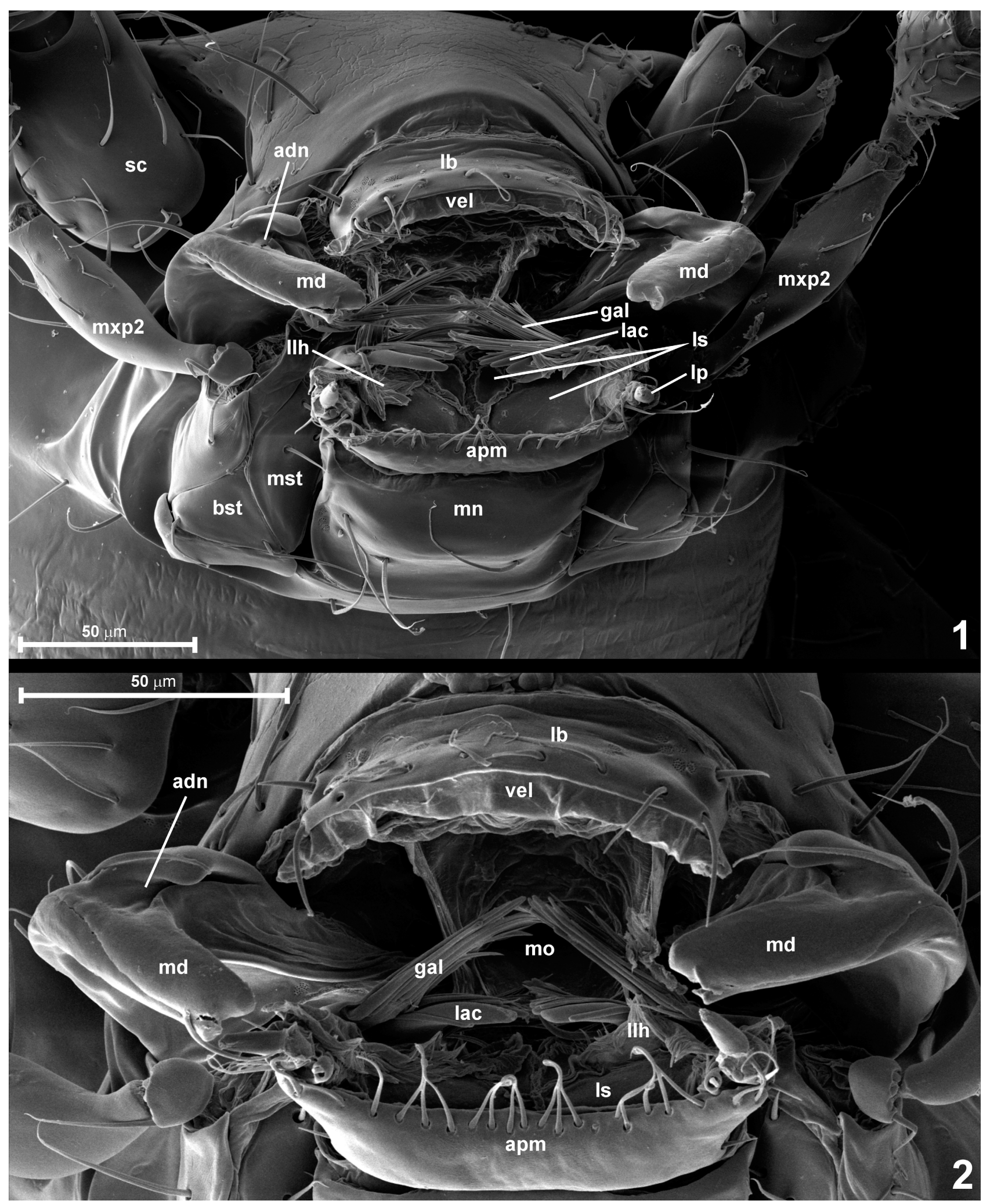

Figs 1 and 2. Structures of Cephennium majus used to capture and consume prey. Anterior portion of head in anterior view. Abbreviations: adn - anterodorsal notch; apm - anterior premental margin; bst - basistipes; gal - galea; lac - lacinia; lb - labrum; llh - lateral lobe of hypopharynx; Ip - labial palp; ls - labial sucker; md - mandible; mn - mentum; mo - anatomical mouth opening; mst - mediostipes; mxp - maxillary palpomere II; sc - scape; vel - marginal velum of labrum.

Phase II: penetration of the mite's cuticle (about 40 $\min$ )

About 5 min after capturing the mite, while the prey was lifted and not touching the ground, the beetles were ob- served with one mandible broadly open and not moving, whereas the other mandible started making short scraping movements within the area delimited by the labrum and prementum. The mite's legs (both in ptyctimous and non- 

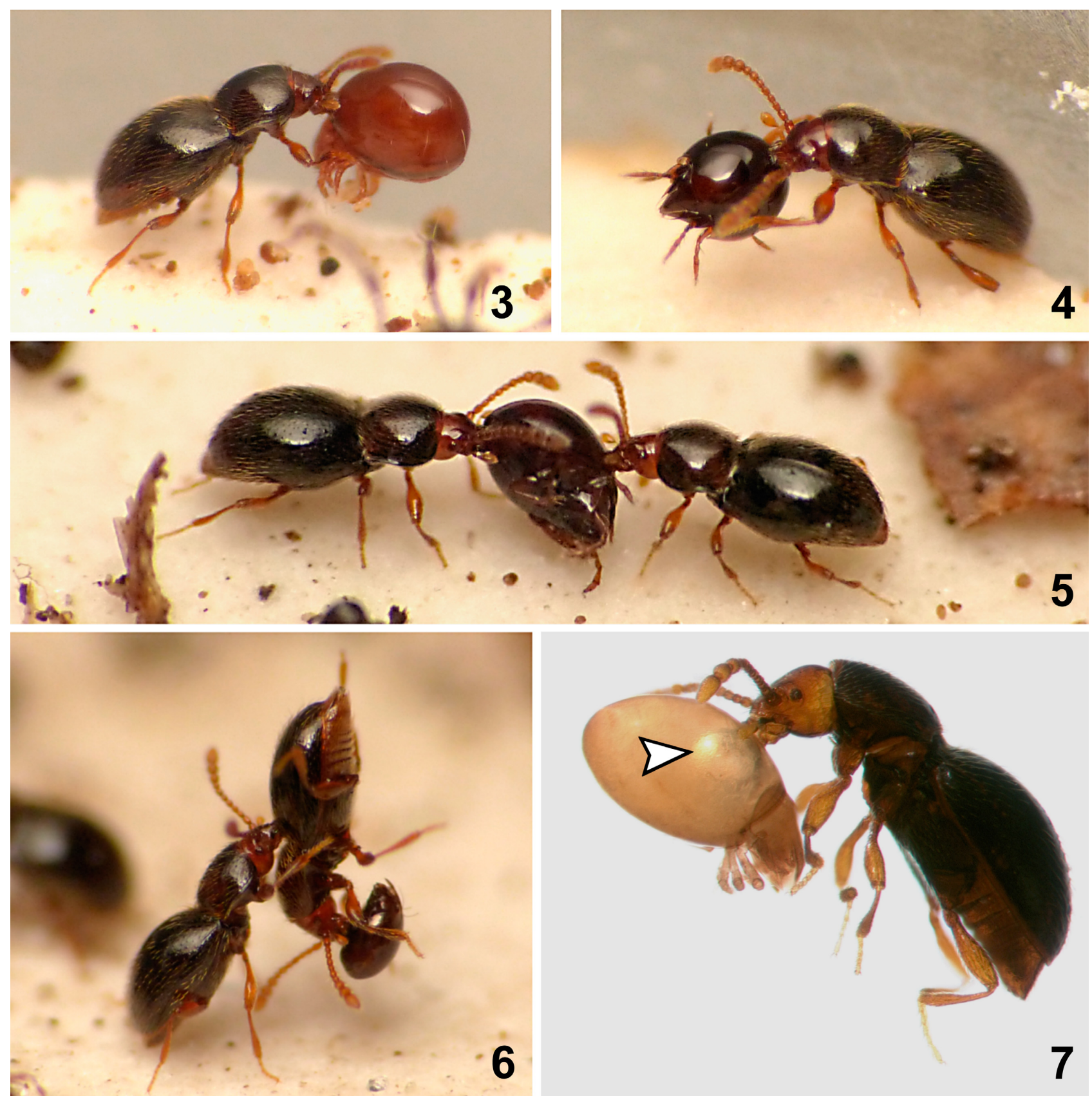

Figs 3-7. Photographs of Cephennium majus feeding on ptyctimous (3) and non-ptyctimous (4) Oribatida, two beetles attacking the same mite (5), beetle attacking another Cephennium that is feeding on an Oribatida mite (6), C. majus preserved during feeding on a ptyctimous mite, photographed in ethanol; arrow indicates air bubble inside prey (7).

ptyctimous taxa) typically made chaotic movements and the beetle's fore legs touched the mite (occasionally by some beetles and nearly continuously by others). For most of the time the prey was lifted off the ground, but when the grip was in the posterodorsal region of the idiosoma and the prey's head was pointing in the same direction as the predator's head, the mite often managed to reach for the ground with some of its legs. If this grip was strong enough for the mite to pull itself closer to the arena and touch it with all its legs, it started crawling forward. Beetles counteracted by lifting the mite higher. During manipulations necessary to counteract a mite's escape attempts by lifting the prey again, the beetle's mandibles usually ceased working. In most cases, if the mite was lifted off the ground all of the time, the scraping movements of one mandible continued for 10-15 min, then the position of the mite was barely noticeably adjusted, and the other mandible was used to penetrate the mite's integument. After about 20 min the mite's leg movements weakened and then suddenly became very rapid. As confirmed by taking the prey away and examining its surface (10 observations), these rapid movements marked the moment the perforation of the cuticle was completed, but the mite was still alive. Beetles almost invariably reacted to the increased movements of the prey by ceasing the mandible action and apparently waiting for the prey to decrease its sudden activity, which typically happened within 2-9 min. During this pause beetles usually increased the frequency of palpating 


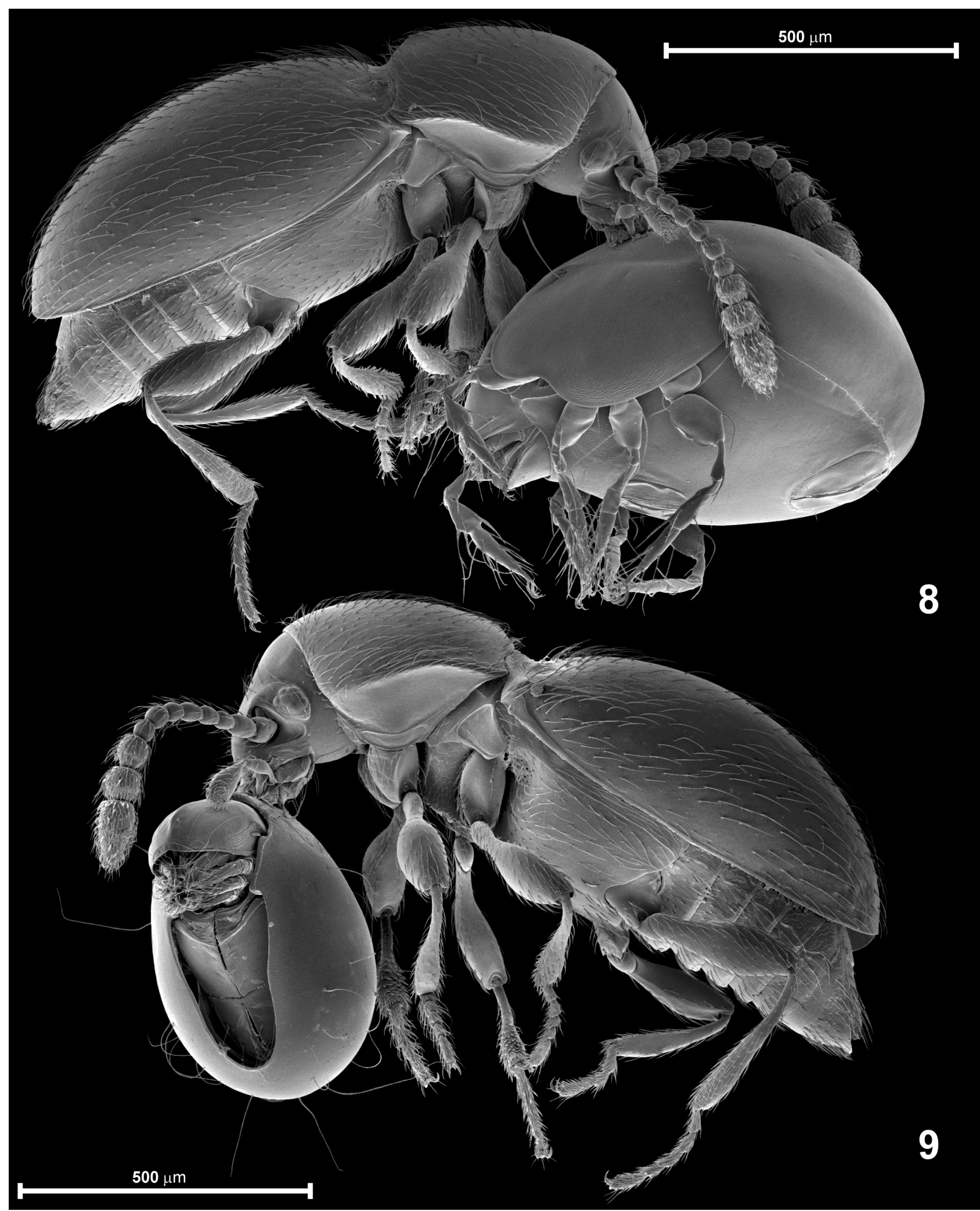

Figs 8 and 9. Scanning electron micrographs of Cephennium ruthenum preserved during feeding on a non-ptyctimous (8) and a ptyctimous (9) mite.

the mite with their maxillary palps. Around the 30th min of this phase leg movements of the prey nearly stopped on the side on which the hole was drilled, but weak leg movements continued on the opposite side. Cephennium resumed working with one mandible, presumably broadening the hole or trying to insert a tip of one mandible deeper, which again caused increased leg movements of the prey followed (usually after a $15-30$-s delay) by a pause in the beetle's efforts. Such cycles of rapidly increased activity of the mite followed by decreased activity of the beetle were repeated 3-4 times before the movements of the prey finally stopped. At this point it was usually possible to see that 


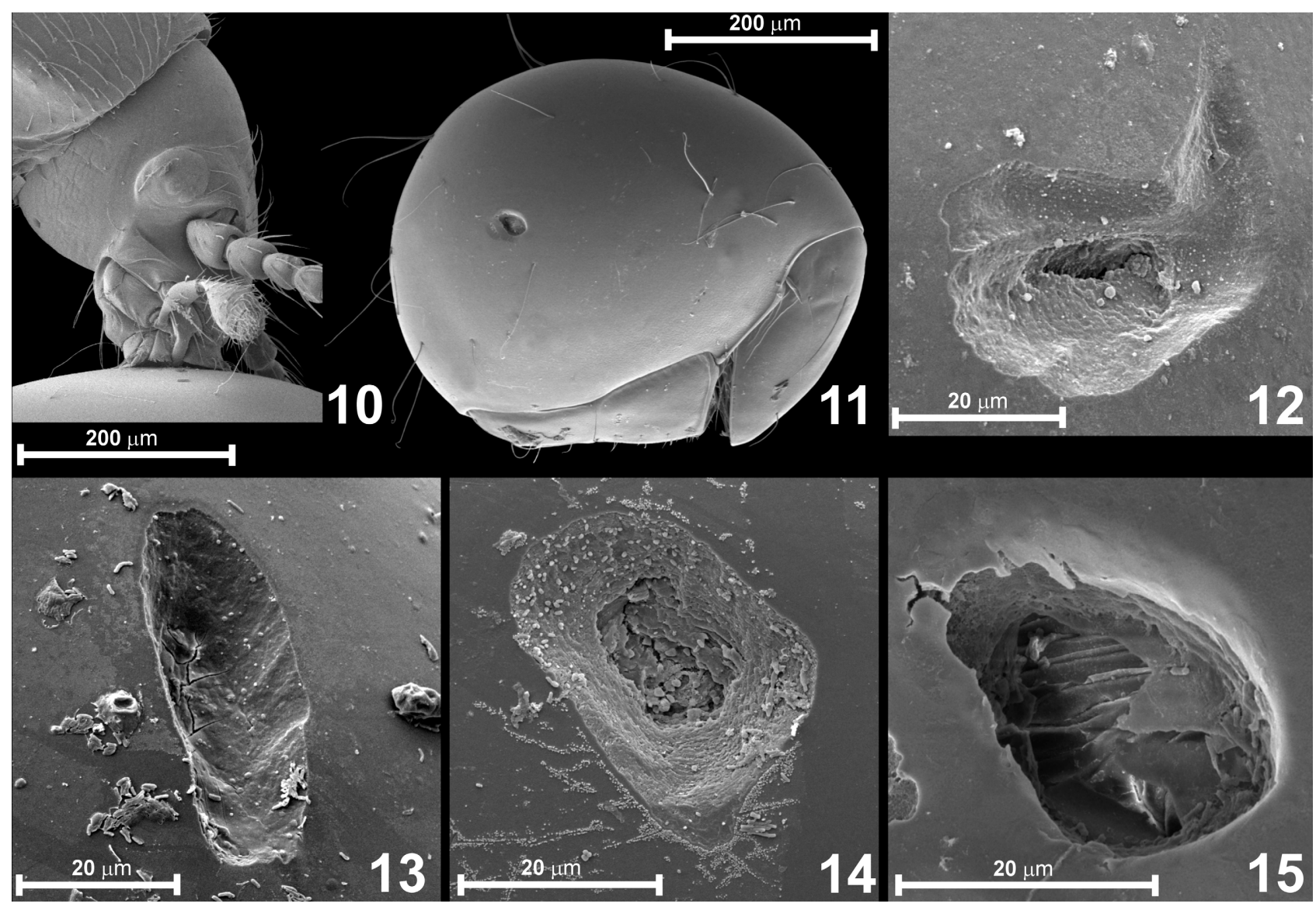

Figs 10-15. Scanning electron micrographs of Cephennium majus preserved during feeding on a ptyctimous mite, contact area (10), Phthiracarus sp. with feeding damage on lateral surface of idiosoma (11), penetration site on the cuticle of Chamobates subglobulus (12), Chamobates cuspidatus (13), Ceratozetes mediocris (14) and Phthiracarus sp. (15).

the tip of one mandible of the beetle was inserted into the hole, the other mandible was broadly open, and the maxillary palps continued palpating the prey, with noticeably more frequent movements of the palp on the same side as the inserted mandible.

\section{Phase III: feeding (7-8 h)}

Close examination (Fig. 10) revealed that when attached to the mite's cuticle, the surface of the prementum that bears the suckers was parallel to the body surface of the mite and the labrum was strongly bent dorsally. When movements of the mite and soon the movements of the beetle's mandibles stopped, both mandibles remained closed and nearly hidden under the labrum and labium. In this phase, illustrated in Fig. 10, the attachment site was completely surrounded by the beetle's mouthparts, which apparently tightly sealed the hole and enabled the injection of digestive juices and ingestion of liquefied tissues. Three beetles observed continuously during the entire feeding process behaved in a similar way during feeding; 20-80 $\mathrm{s}$ after the legs of mite finally stopped moving, the beetle started swinging the mite sideways, lowering its head so that the prey touched the ground. This was followed by walking with the prey held in the beetle's mouthparts; occasionally the beetles lowered their heads and again made swinging movements. This walking-and-swinging behaviour was repeated many times at irregular intervals of sev- eral seconds to several minutes during the entire $7-8 \mathrm{~h}$ of feeding. When beetles with their prey were preserved during this phase of feeding, an air bubble could be seen inside the mite at the pierced site (Fig. 7, arrow). Another round of swinging ended by the detachment and abandonment of the eaten prey.

The only damage caused by the beetles was a tiny hole in the mite's cuticle (Figs 11-15). In rare cases there were one or two shallow and incomplete traces of where a beetle had scraped the surface of mites, in addition to the complete hole through which the beetle fed; in one case a hole with two additional, adjacent traces of scraping were found (Fig. 12). In all non-ptyctimous and most ptyctimous mites the hole was clearly identifiable as a result of scraping (Figs 12-14), but in some Phthiracarus the penetration site had an appearance of being pierced (Fig. 15).

\section{Prey choice}

\section{Prey preferences of C. majus (Table 1; Fig. 16)}

The total of 744 mites offered to 20 adults of $C$. majus consisted of 47 identified species of Oribatida belonging in 22 families and 17 superfamilies, and 9 identified species of Mesostigmata belonging in 5 families and 2 superfamilies (Table 1). All the mesostigmatan Acari tested were rejected. Cephennium majus ate 301 armoured mites, i.e., $44.44 \%$ of all the Oribatida offered, which belonged predominantly to Phthiracaridae $(72.07 \%$ of offered phthi- 
Table 1. Systematic list of mite species offered, accepted and rejected by Cephennium majus and C. ruthenum in laboratory experiments. The two species of Liacaridae found in Poland for the first time during the present study are marked with an asterisk.

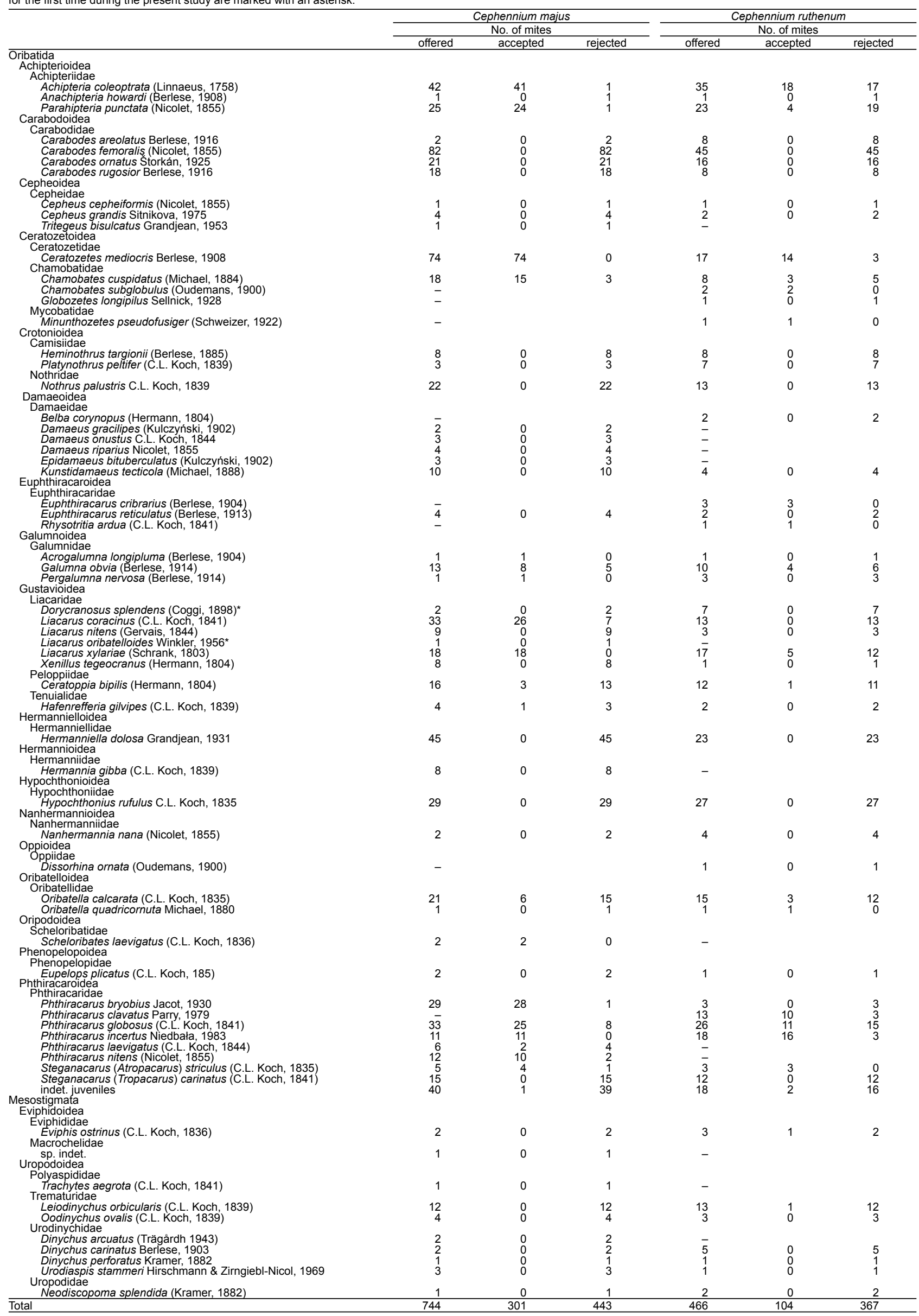




\section{Cephennium majus}

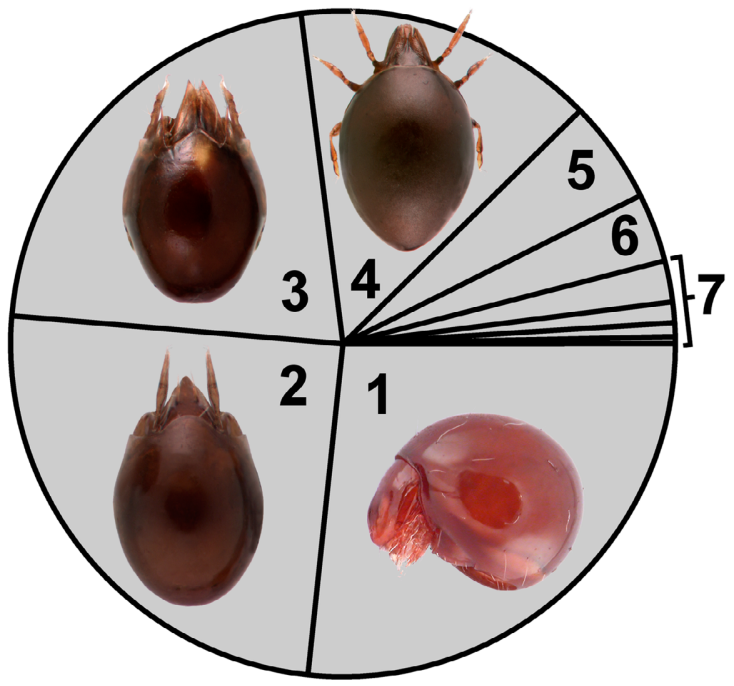

1. Phthiracaridae $(26.7 \%)$

2. Ceratozetidae $(24.7 \%)$

3. Achipteriidae (21.7\%)

4. Liacaridae $(14.7 \%)$

5. Chamobatidae (5.0\%)

6. Galumnidae $(3.3 \%)$

7. Oribatellidae, Peloppiidae, Scheloribatidae, Tenuialidae (together 4\%)

\section{Cephennium ruthenum}

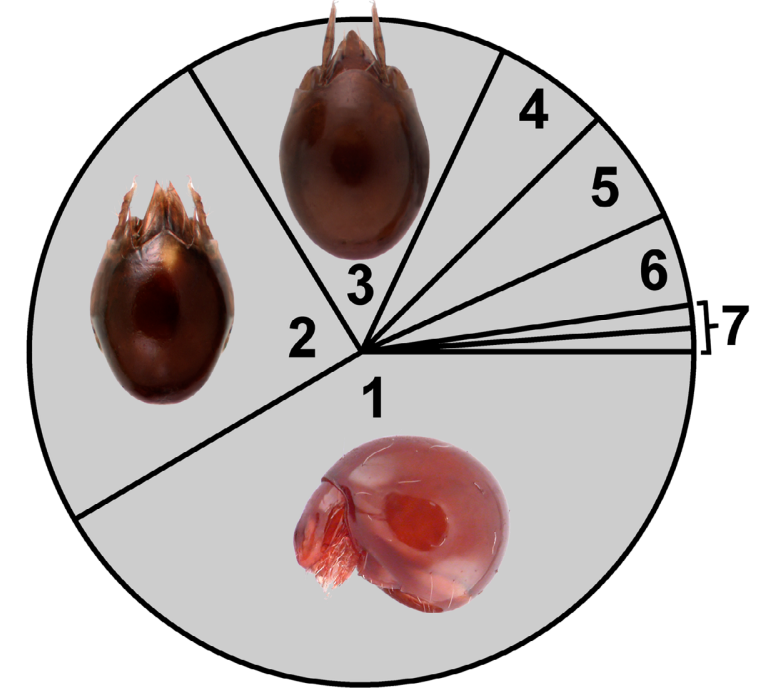

1. Phthiracaridae $(41.6 \%)$

2. Achipteriidae $(24.7 \%)$

3. Ceratozetidae $(15.7 \%)$

4. Liacaridae $(5.6 \%)$

5. Chamobatidae (5.6\%)

6. Galumnidae $(4.5 \%)$

7. Mycobatidae, Oribatellidae (together 2.2\%)

Fig. 16. Percentages of prey consumed by Cephennium majus and $C$. ruthenum organized by taxon with examples of species belonging to each family: Phthiracarus sp. (Phthiracaridae), Ceratozetes mediocris (Ceratozetidae), Achipteria coleoptrata (Achipteriidae) and Liacarus coracinus (Liacaridae).

racarids, $26.7 \%$ of eaten oribatids), Ceratozetidae $(100 \%$ and $24.7 \%$, respectively) and Achipteriidae (95.59\% and $21.7 \%)$. The remaining families made up a small portion of the diet: Liacaridae (61.97\% and $14.7 \%)$, Chamobatidae $(83.33 \%$ and $5.0 \%)$, Galumnidae $(66.67 \%$ and $3.3 \%)$ and Oribatellidae, Peloppiidae, Scheloribatidae and Tenuialidae together made up $27.27 \%$ of offered specimens and $4 \%$ of the oribatids eaten (Fig. 16). At the species level, the most readily accepted mites were Ceratozetes mediocris (Ceratozetidae), Phthiracarus incertus (Phthiracaridae), Achipteria coleoptrata (Achipteriidae), Phth. bryobius (Phthiracaridae), Parahipteria punctata (Achipteriidae), Liacarus coracinus (Liacaridae) and Phth. globosus (Phthiracaridae); 75.6-100\% of these species were eaten by the beetles. It is worthy to note that as many as 74 individuals of $C$. mediocris and 42 of $A$. coleoptrata were offered to beetles and all (C. mediocris) or all but one (A. coleoptrata) were eaten.

Of all the oribatid mites provided (ranging in body length from $0.35 \mathrm{~mm}$ for the smallest species, Chamobates cuspidatus, to $1.50 \mathrm{~mm}$ for the largest, Damaeus onustus) only those with body lengths of $0.35-0.975 \mathrm{~mm}$ were eaten by $C$. majus. The mites eaten $(\mathrm{n}=300)$ had a median body length (quartiles in square brackets) of $0.55 \mathrm{~mm}$ $[0.50,0.625]$, which is significantly smaller $(U=28139 ; p$ $<<0.001)$ than the median $0.65[0.575,0.80]$ of those not eaten $(n=375)$. Phthiracaridae, the mites that were most frequently eaten $(n=80)$, had a median body length 0.525 $\mathrm{mm}[0.475,0.625]$, which is significantly smaller $(\mathrm{U}=$ $595.5 ; \mathrm{p}<<0.001)$ than the median of 0.675 [0.587, 0.762] of those $(n=31)$ not eaten.

\section{Prey preferences of $C$. ruthenum (Table 1; Fig. 16)}

The total of 466 mites offered to 10 adults of $C$. ruthenum consisted of 44 identified species of Oribatida belonging to 21 families and 16 superfamilies, and 7 species of Mesostigmata belonging to 4 families and 2 superfamilies (Table 1). Only two mesostigmatan Acari were accepted, one specimen each of Eviphis ostrinus and Leiodinychus orbicularis. Cephennium ruthenum ate 100 armoured mites, i.e., only $23.81 \%$ of all the Oribatida offered, which belonged predominantly to Phthiracaridae (48.68\% of all offered phthiracarids and $41.6 \%$ of eaten oribatids), Achipteriidae $(37.29 \%$ and $24.7 \%$, respectively) and Ceratozetidae $(82.35 \%$ and $15.7 \%)$, with only a small number of Liacaridae (12.19\% and 5.6\%), Chamobatidae (45.45\% and 5.6\%), Galumnidae (30.77\% and 4.5\%), and Mycobatidae and Oribatellidae (together $11.76 \%$ of offered specimens and $2.2 \%$ of the oribatids eaten) in the diet (Fig. 16). At the species level, the most readily accepted mites were Phthiracarus incertus (Phthiracaridae), Ceratozetes mediocris (Ceratozetidae), Achipteria coleoptrata (Achipteriidae), Phth. globosus (Phthiracaridae), Liacarus xylariae (Liacaridae) and Parahipteria punctata (Achipteriidae); $17.40-84.21 \%$ of these mites were eaten by the beetles. 


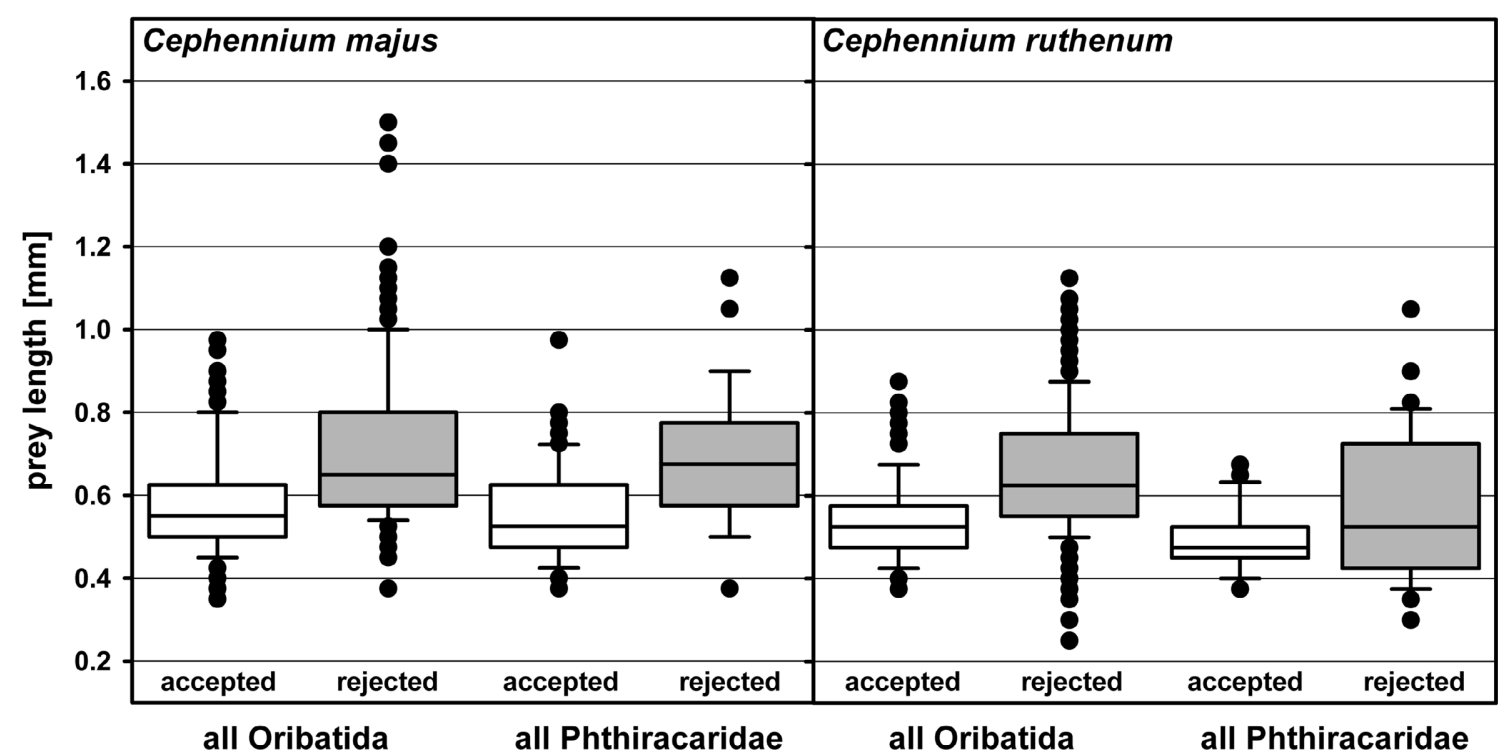

Fig. 17. Distributions of the body lengths of Oribatida eaten (accepted) and not eaten (rejected) by Cephennium majus and C. ruthenum; the median, 10th, 25th, 75th, 90th percentiles and outliers are shown.

Of all the oribatid mites provided (ranging in body length from $0.25 \mathrm{~mm}$ for the smallest species, Dissorhina ornata, to $1.125 \mathrm{~mm}$ for the largest, Dorycranosus splendens) only those with body lengths of $0.375-0.875 \mathrm{~mm}$ were eaten by C. ruthenum. The mites eaten $(\mathrm{n}=88)$ had a median body length (quartiles in square brackets) of $0.525 \mathrm{~mm}[0.475$, $0.575]$, which is significantly smaller $(U=7604.5 ; \mathrm{p}<<$ $0.001)$ than the median of $0.625[0.55,0.75]$ of those not eaten $(n=347)$. Phthiracaridae, the mites that were most frequently eaten $(\mathrm{n}=36)$, had a median body length of $0.475 \mathrm{~mm}[0.45,0.525]$, which is smaller, but statistically not significantly different $(U=616.5 ; p=0.07)$ from the median of $0.525[0.45,0.70]$ of those $(n=45)$ not eaten.

\section{Time taken to eat the mites}

Relationships between the feeding time and the body length of the prey were analyzed only for $C$. majus. The beetles were offered mites belonging to four categories: small, non-ptyctimous (Chamobates cuspidatus; body length of $0.34-0.375 \mathrm{~mm}$ ); medium-sized, ptyctimous (Phthiracarus sp.; body length of 0.39-0.45 mm); medium-sized, non-ptyctimous (Ceratozetes mediocris; body length of 0.475-0.575); large, non-ptyctimous (Chamobates subglobulus; body length of $0.64-0.70 \mathrm{~mm}$ ). Results (Fig. 18) show that the entire process from attack to abandonment of the empty mite shells takes $2.00-10.37 \mathrm{~h}$ for mites ranging in length from $0.34-0.70 \mathrm{~mm}$, with a high variation in the time for each of the oribatid species tested. When only the feeding time (i.e., the time from killing the mite to abandonment of the empty shell) was considered, the values ranged from $1.17 \mathrm{~h}$ to $9.57 \mathrm{~h}$. The median values of the total process and the feeding time were clearly lowest for the smallest mites and highest for the largest prey, but comparable in the case of the medium-sized ptyctimous Phthiracarus and non-ptyctimous Ceratozetes. Interestingly, when the access time (i.e., the time from attack to the killing of the mite) was analyzed (Fig. 18, right panels) it was found that despite the great variation in the values, the median time (quartiles in square brackets) for all nonptyctimous mites was low and equal to $0.38 \mathrm{~h}[0.25,0.50]$ (small Ch. cuspidatus), $0.67 \mathrm{~h}[0.62,0.92]$ (medium-sized C. mediocris) and $0.63 \mathrm{~h}[0.54,1.42]$ (large Ch. subglobulus). The access time for the ptyctimous medium-sized Phthiracarus, however, was much higher than the time recorded for the much larger non-ptyctimous Ch. subglobu$l u s$, with a median value of $1.23 \mathrm{~h}[1.17,1.58]$.

\section{Differences in prey preferences of C. majus and $C$. ruthenum}

Direct comparisons between Cephennium species are difficult because different numbers of mites of some species and families were offered to C. majus and C. ruthenum. However, the Phthiracaridae and Liacaridae offered to both species made up a similar portion of the living menu: $16.44 \%$ and $17.85 \%$ of all oribatids offered to $C$. majus and C. ruthenum, respectively, consisted of Phthiracaridae; $10.52 \%$ and $9.76 \%$ of all oribatids offered to $C$. majus and C. ruthenum, respectively, consisted of Liacaridae. Therefore, the remarkable difference in the numbers of mites belonging to these families (see Phthiracaridae and Liacaridae plots in Fig. 16) eaten by $C$. majus and $C$. ruthenum cannot be attributed to a disproportionate offering of these two mite families. Of the living menu, 10.96\% and only $4.04 \%$ of all oribatids offered to C. majus and C. ruthenum, respectively, consisted of Ceratozetidae; $10.07 \%$ and $14.05 \%$ of all oribatids offered to C. majus and $C$. ruthenum, respectively, consisted of Achipteriidae. Consequently, differences in the number of mites of these families accepted by Cephennium may be a combined effect of a different menu offered to each species of beetle and possibly different prey preferences.

The oribatids eaten by the larger $C$. majus $(\mathrm{n}=300)$ had a median body length (quartiles in square brackets) of $0.55 \mathrm{~mm}[0.50,0.625]$, which is significantly larger $(\mathrm{U}=$ 10315.5; $\mathrm{p}=0.0017)$ than the median $0.525 \mathrm{~mm}[0.475$, 0.575 ] of those eaten by the smaller C. ruthenum $(\mathrm{n}=88)$. 

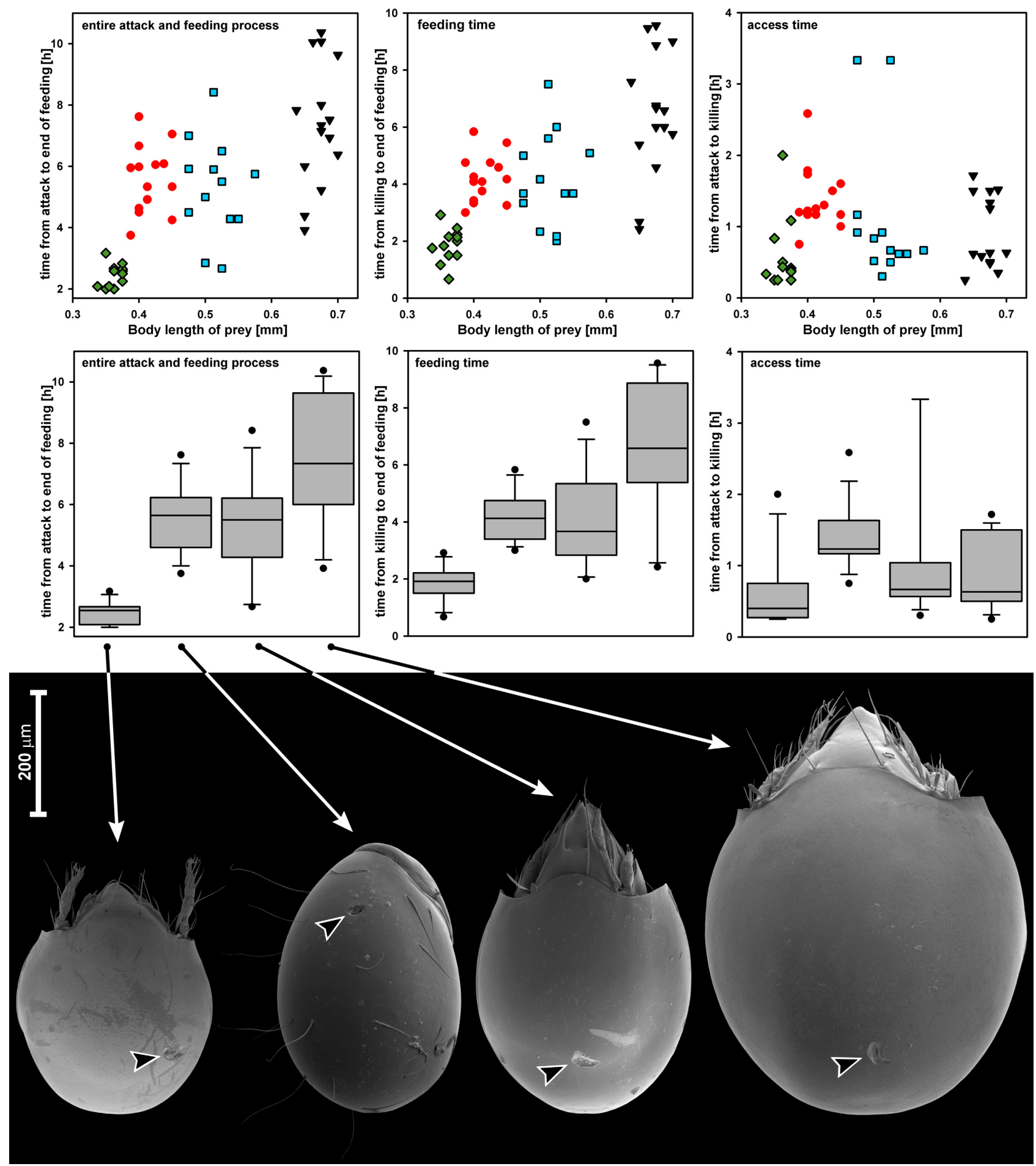

Fig. 18. Time course of attack and feeding by Cephennium majus on four species of Oribatida. Upper panel: each point in the plot represents a single mite eaten. Middle panel: results for each species of mite are represented by a box plot, the median, 10 th, 25 th, $75^{\text {th }}$ and 90th percentiles and outliers are shown. Bottom panel: Species of mites of the four size categories (from left to right, to the same scale) used in experiments: small, non-ptyctimous Chamobates cuspidatus; medium-sized, ptyctimous Phthiracarus sp.; medium-sized, nonptyctimous Ceratozetes mediocris; large, non-ptyctimous Chamobates subglobulus (feeding damage indicated by arrows).

When only Phthiracaridae mites were compared, those eaten by C. majus $(\mathrm{n}=80)$ had a median body length of $0.525 \mathrm{~mm}[0.475,0.625]$, which is only slightly but significantly larger $(U=1025.5 ; p=0.013)$ than the median of $0.475 \mathrm{~mm}[0.45,0.525]$ of those eaten by $C$. ruthenum $(n=36)$.

\section{Morphological structures of the mites eaten and rejected by $C$. majus and $C$. ruthenum}

All Oribatida species eaten have a subglobose body form, rigid cuticle, smooth or only finely and shallowly reticulate cuticle, short legs and at most a sparsely setose idiosoma. Both ptyctimous and non-ptyctimous mites were eaten; 
among the non-ptyctimous oribatids there were forms with and without pteromorphs.

Both species of Cephennium rejected all individuals of oribatids belonging to the following families: Carabodidae (200 individuals offered), Cepheidae (9), Camisiidae (26), Nothridae (35), Damaeidae (24, but only 2 offered to $C$. majus), Hermanniellidae (68), Hermanniidae (8 individuals offered only to C. majus), Hypochthoniidae (56), Nanhermanniidae (6) and Phenopelopidae (3). These oribatids have the following characters that were not present in the accepted prey: body flattened, not subglobose (Camisiidae, Nothridae, Hypochthoniidae); body weakly sclerotized, relatively soft (Hypochthoniidae); the idiosoma with deep, irregular sculpture (Carabodidae); reticulation on the idiosoma distinctly coarser than that of the accepted species (Cepheidae, Camisiidae, Nothridae, Euphthiracaridae, Hermanniellidae, Hermanniidae, Nanhermanniidae and Phenopelopidae); the body covered to various extents with soil particles (some Camisiidae, Nothridae and Damaeidae); or unusually long and spiny legs (Damaeidae). Among the other families of which some individuals were accepted and some rejected, the most striking example is the Phthiracaridae: species of Phthiracarus that have a smooth or indistinctly reticulate idiosoma and Steganacarus striculus in which it is finely reticulated were accepted, whereas Steganacarus carinatus (27 individuals offered) in which it is coarsely reticulated was rejected.

\section{DISCUSSION}

The genus Cephennium belongs to the large tribe Cephenniini, whose synapomorphy is a strongly modified prementum bearing paired adhesive pads, designated functional "suckers" by Jałoszyński \& Beutel (2012) on the basis of a detailed histological study. The subject of that study was Cephennium thoracicum (Müller \& Kunze), whose adults are very similar to those of $C$. majus and $C$. ruthenum. All of these beetles use premental suckers to capture oribatid mites, and short, relatively blunt mandibles to penetrate the prey's cuticle by prolonged scraping of its surface. After scraping a tiny hole, only about $20 \mu \mathrm{m}$ wide, a beetle feeds on liquefied tissues of the mite. Premental pads or discs can also be found in another genus of Scydmaeninae, Stenichnus Thomson (Jałoszyński, 2013), belonging to the Glandulariini. However, in Stenichnus there are two discs (four to six in Cephenniini) and the labium has a small prementum and large labial palps, whereas the labium in Cephenniini has tiny palps and large prementum. Moreover, Stenichnus species use the prementum only in the initial phase of attack, relying predominantly on long, falciform mandibles, which are used to kill the prey in a way similar to that previously documented for scydmaenines that use variants of the "cutting technique", i.e., they attack the gnathosoma and break off movable parts and feed through the resulting opening (Jałoszyński, unpubl. data). Although observations of the feeding behaviour have been made only on Cephennium species (Schuster, 1966a, b; Schmid, 1988; Jałoszyński \& Beutel, 2012; present study), similarly modified mouthparts are found in all genera of
Cephenniini (Jałoszyński, 2011, 2012c, 2014; Jałoszyński $\&$ Beutel, 2012). These modifications, and especially the premental suckers, suggest that all Cephenniini may be specialist predators of armoured mites.

The previously suggested mechanism of feeding, by sealing the hole scraped in the mite's cuticle using membranous mouthparts and then injecting digestive juices into the mite and ingesting the liquefied tissues (Jałoszyński \& Beutel, 2012), which was inferred from a morphological study, is supported by our observations. As seen in Fig. 10 , when the prey's cuticle is penetrated and the beetle's mandibles remain in a closed or nearly closed position, the attachment site is formed by the membranous epipharynx and prementum tightly adhering to the mite, and the anterolateral surface of the mandibles are pressed against the mite. The lateral portions of the labrum and the dorsal surface of the mandibles are tightly interlocked into the anterodorsal notch of each mandible, into which the sides of labrum with the membranous marginal velum fit. The lateral area between the sides of prementum and ventral surface of each mandible is sealed by the membranous lateral lobes of the hypopharynx and presumably also by the lacinia and galea. Such an arrangement of mouthparts allows for the anatomical mouth opening of the beetle to be aligned with the hole in the mite's cuticle. The distal portions of the lacinia and galea, if arranged in a similar way as in Fig. 2, may facilitate transfer of liquids by capillary action. During feeding, an air bubble can be observed increasing in size inside the mite (Fig. 7), suggesting that soft tissues are gradually dissolved and ingested by Cephennium. The attachment is so strong that it was possible to kill and preserve beetles during feeding without detaching their prey (Figs 8-9). Moreover, the beetles did not release their grip even when attacked, lifted and turned upside down by other beetles (Fig. 6). The reason for such a strong attachment was suggested by Jałoszyński \& Beutel (2012), who found that only the initial phase of prey capture may require muscular contractions, while the grip can be maintained effortlessly, with labial muscles relaxed, solely by the passive action of the suckers.

Both species of Cephennium successfully attacked and ate ptyctimous and non-ptyctimous mites, and among the latter category, taxa with and without protective pteromorphs. The defence mechanism used by ptyctimous mites, retraction of all the legs beneath the closing shield of the prodorsum, protects oribatids against predators that rely on their mandibles to capture prey by grasping its legs or by attacking weakly sclerotized, fragile areas on the prey's body. It was previously demonstrated that this defence system is inefficient against specialized Scydmaeninae that rely on noxious digestive juices to weaken the mite, and when the prodorsum is even slightly opened, further attack is focused on opening it further and crushing the ventral plates (Jałoszyński \& Olszanowski, 2013). In non-ptyctimous oribatids, the pteromorphs may protect the proximal portions of legs from being grabbed and cut off by predators. Both adaptations are easily overcome by $\mathrm{Ce}$ phennium, which attack the mite's armoured idiosoma and 
not the fragile ventral structures. In this way Cephennium has access to a rich source of food that is not available to other predators.

Oribatids that seem to successfully avoid predation by Cephennium were represented in this study by the families Carabodidae, Cepheidae, Camisiidae, Nothridae, Damaeidae, Hermanniellidae, Hermanniidae, Hypochthoniidae, Nanhermanniidae and Phenopelopidae. The eaten mites are typically subglobose, heavily sclerotized, with the surface of the idiosoma smooth or only shallowly and finely microreticulate, covered with sparse setae or nearly asetose and with short legs. In contrast, the mites that were rejected by Cephennium lack these characteristics: some of them are flattened, not subglobose; some have the cuticle weakly sclerotized and relatively soft, others are deeply sculptured or coarsely reticulate; some have strikingly long and spiny legs; or their bodies are covered with soil particles. Often more than one of these characters occur in members of a family, e.g., the Nothridae are not subglobose, have legs distinctly longer than those of mites accepted by Cephennium, the idiosoma is coarsely reticulate and often has accumulations of soil particles in impressed areas on its dorsum; Damaeidae have long and spiny legs and often carry a protective crust of soil particles. Carabodidae, Nothridae, Damaeidae and Hermanniellidae seem particularly wellprotected; species belonging to these families are not eaten by any of the scydmaenine taxa so far tested (Jałoszyński \& Olszanowski, 2013, 2015 and present study).

Species of Cephennium inhabit leaf litter and rotten wood on the forest floor, and therefore a comparison of their prey preferences with the previously tested Scydmaenus rufus, a typical compost species, would be irrelevant. The communities of mites found in forest soils and those in garden compost differ markedly. However, another common and already studied species of Scydmaeninae, Euconnus pubicollis, can be found in the same habitat as C. majus and C. ruthenum, (Jałoszyński \& Olszanowski, 2013). Indeed, when collecting beetles for the present study, numerous individuals of E. pubicollis were found together with Cephennium in the sifted leaf litter. Therefore, all three of these species in nature may have access to the same mite community, unless they are associated with different and as yet unknown microhabitats. Comparison of their prey preferences gives interesting results. Under laboratory conditions both species of Cephennium and E. pubicollis ate Phthiracaridae, but while for Cephennium species this family represented $26.7-41.6 \%$ of the diet, over $90 \%$ of the mites eaten by Euconnus are phthiracarids. It seems that various species of Scydmaeninae that occur in the same habitat can reduce competition for prey by specializing on different mite families. However, care must be taken when comparing results of different experiments and observations, as the composition of the menu offered to the various beetle species was not the same.

For the same reason it is difficult to directly compare prey preferences of $C$. majus and $C$. ruthenum. A different number of mites of some species and families were offered to these species, e.g., $10.96 \%$ and $4.04 \%$ of all oribatids offered to $C$. majus and $C$. ruthenum, respectively, were Ceratozetidae; and $10.07 \%$ and $14.05 \%$ of all oribatids offered to $C$. majus and $C$. ruthenum, respectively, were Achipteriidae. These differences demonstrate a weakness of random-choice experiments carried out under laboratory conditions and indicate the need of a more reproducible and comparable procedure. The sifted samples of leaf litter used as the source of mites in the present study were mixed before being placed in the three containers, the same method of collecting mites was consistently used, and all the mites collected were pooled, divided into three approximately equal parts, and given to the three groups of beetles. However, even this procedure resulted in differences in the three sets of mites in terms of species composition and abundance. On the other hand, this is the only feasible way of offering the beetles a broad spectrum of potential prey within a reasonable time. It is nearly impossible to manually pick an equal number of species and individuals of living mites to ensure that the same set of oribatids is given to each group of beetles; such an approach would require identifying living mites to the species level. Although the methodology is not perfect it does provide knowledge of those mites that are acceptable (i.e., edible) for particular scydmaenines, and how these beetles breach the defence systems of otherwise well-protected armoured mites. Among the prey-associated factors, the choice of mites of a certain body length seems well-documented and not or weakly biased by the method used. All Scydmaeninae species tested so far selected mites within a certain size range, which was in each case narrower than the body length of all the prey available, even if the most preferred oribatid species are compared. Euconnus pubicollis selected individuals of Phthiracarus with a median body length of $0.625 \mathrm{~mm}[0.55,0.70]$, whereas the median body length of all the individuals of the same genus offered was $0.74 \mathrm{~mm}$ $[0.675,0.775]$. A similar pattern for all mites, or all Oribatida, or (in the case of Cephennium) all Phthiracaridae, is recorded in a study of Scydmaenus rufus (Jałoszyński \& Olszanowski, 2015) and in the present results. Also, the feeding time clearly increases with increasing prey body length for Euconnus and Cephennium (not studied for Scydmaenus rufus).

An interesting difference between C. majus and C. ruthenum was that the former species readily ate Liacaridae, which constituted $14.7 \%$ of all the oribatids accepted (61.97\% of offered liacarids were eaten), whereas the corresponding value for $C$. ruthenum was only $5.6 \%$ (Fig. 16) (and only $12.19 \%$ of offered liacarids were eaten). Liacaridae made up a similar percentage of the offered menu for both species $(10.52 \%$ for $C$. majus and $9.76 \%$ for $C$. ruthenum). The adults of Cephennium ruthenum are slightly smaller than those of $C$. majus and this difference was reflected in their choice of prey (Fig. 17). The Liacaridae tested are large-bodied mites, which are close to the upper prey body length limit for both species of Cephennium, but within the acceptable range for the larger $C$. majus and at the upper edge of the optimum range for the smaller $C$. ruthenum. 
One of the most interesting results was that it took $\mathrm{Ce}$ phennium considerably longer to kill Phthiracaridae than the non-ptyctimous oribatids, even when the latter were much larger than phthiracarids (Fig. 18, right middle). Apparently it is more difficult to kill mites belonging to this family, but it is still unknown why. However, when analyzing the feeding damage caused by beetles to the cuticle of ptyctimous and non-ptyctimous mites, it was noted that only in phthiracarids was the typical scraping damage (Figs 12-14) sometimes replaced by what can be interpreted as piercing damage (Fig. 15). Similar piercing damage on phthiracarids was previously illustrated by Jałoszyński \& Beutel (2012). As this type of damage cannot always be distinguished using light microscopy, the frequency of each damage type was not studied in detail. The structure and properties of the cuticle in this group of Oribatida may be responsible for the observed differences, both in the type of damage and time required to kill the prey. This interesting problem remains to be resolved.

ACKNOWLEDGEMENTS. We are indebted to W. Niedbała and J. Błoszyk (Faculty of Biology, A. Mickiewicz University, Poznań) for identifying some of the ptyctimous and uropodine mites, respectively, and to A. Siudzińska (Laboratory of Electron Microscopy, Wrocław Research Centre EIT+) for taking the SEM images.

\section{REFERENCES}

De Marzo L. 1983: Osservazioni sulla ovideposizione e sul ciclo larvale in Mastigus pilifer Kraatz (Coleoptera, Scydmaenidae). - Entomologica (Bari) 18: 125-136.

Grebennikov V.V. \& Newton A.F. 2009: Good-bye Scydmaenidae, or why the ant-like stone beetles should become megadiverse Staphylinidae sensu latissimo (Coleoptera). - Eur. J. Entomol. 106: 275-301.

JAŁOSZYŃSKI P. 2011: Cephenniini with prothoracic glands and internal 'cavities': new taxa, enigmatic characters and phylogeny of the Cephennomicrus group of genera (Coleoptera, Staphylinidae, Scydmaeninae). - Syst. Entomol. 36: 470-496.

JAŁOSZYŃSKI P. 2012a: Adults of European ant-like stone beetles (Coleoptera: Staphylinidae: Scydmaeninae) Scydmaenus tarsatus Müller \& Kunze and S. hellwigii (Herbst) prey on softbodied arthropods. - Entomol. Sci. 15: 35-41.

JAŁOSZYŃSKI P. 2012b: Observations on cannibalism and feeding on dead arthropods in Scydmaenus tarsatus (Coleoptera: Staphylinidae: Scydmaeninae). - Genus 23: 25-31.

JAŁOSZYŃSKI P. 2012c: Beetles with 'trochantelli': phylogeny of Cephenniini (Coleoptera: Staphylinidae: Scydmaeninae) with focus on Neotropical genera. - Syst. Entomol. 37: 448-477.
JAŁOSZYŃSKI P. 2013: Revision of subgenera of Stenichnus Thomson, with review of Australo-Pacific species (Coleoptera, Staphylinidae, Scydmaeninae). — Zootaxa 3630: 39-79.

JAŁOSZYŃSKI P. 2014: Phylogeny of a new supertribe Cephenniitae with generic review of Eutheiini and description of a new tribe Marcepaniini (Coleoptera: Staphylinidae: Scydmaeninae). Syst. Entomol. 39: 159-189.

JAŁOSZYŃSKI P. 2016: 14.5. Scydmaeninae. In Beutel R.G. \& Leschen R.A.B. (eds): Handbook of Zoology. Arthropoda: Insecta. Coleoptera, Beetles. Morphology and Systematics, Vol. 1, 2nd Ed. Walter de Gruyter, Berlin, pp. 376-385.

JAŁOSZYŃSKI P. \& BeUtel R.G. 2012: Functional morphology and evolution of specialized mouthparts of Cephenniini (Insecta, Coleoptera, Staphylinidae, Scydmaeninae). - Arthr. Struct. Dev. 41: 593-607.

JAŁOSZYŃSKi P. \& KILIAN A. 2012: Larval morphology of Scydmaenus tarsatus and S. hellwigii, with notes on feeding behaviour and a review of bibliography on preimaginal stages of antlike stone beetles (Coleoptera: Staphylinidae, Scydmaeninae). - Eur. J. Entomol. 109: 587-601.

JAŁosZYŃSKI P. \& OlsZANOWSKI Z. 2013: Specialized feeding of Euconnus pubicollis (Coleoptera: Staphylinidae: Scydmaeninae) on oribatid mites: Prey preferences and hunting behaviour. - Eur. J. Entomol. 110: 339-353.

JAŁOSZYŃSKi P. \& OLSZANOWSKi Z. 2015: Feeding of Scydmaenus rufus (Coleoptera: Staphylinidae, Scydmaeninae) on oribatid and uropodine mites: Prey preferences and hunting behaviour. - Eur. J. Entomol. 112: 151-164.

Leleup N. 1968: Révision des Mastigini de l'Afrique du Sud. Ann. Mus. R. Afr. Centr. Tervuren (Sci. Zool.) 166: 1-107.

Molleman F. \& Walter D.E. 2001: Niche segregation and canopeners: Scydmaenid beetles as predators of armoured mites in Australia. In Halliday R.B., Walter D.E., Proctor H.C., Norton R.A. \& Colloff M.J. (eds): Acarology: Proceedings of the 10th International Congress. CSIRO, Melbourne, pp. 283-288.

Newton A.F. \& Franz H. 1998: World catalog of the genera of Scydmaenidae (Coleoptera). - Kol. Rundsch. 68: 137-165.

O'Keefe S.T. \& Monteith G.B. 2001: Clidicus abbotensis O'Keefe, a new species of Scydmaenidae (Coleoptera: Staphylinoidea) from Australia with description of the larva. - Mem. Queensl. Mus. 46: 211-223.

ReItTer E. 1909: Fauna Germanica. Die Käfer des Deutschen Reiches. Vol. 2. Lutz KG, Stuttgart, 392 pp.

SCHMID R. 1988: Morphologische Anpassungen in einem RauberBeute-System: Ameisenkafer (Scydmaenidae, Staphylinoidea) und gepanzerte Milben (Acari). — Zool. Jb. Abt. Syst. Ökol. Geogr. Tiere 115: 207-228.

SCHUSTER R. 1966a: Über den Beutefang des Ameisenkäfers Cephennium austriacum Reitter. - Naturwissenschaften 53: 113.

SCHUSTER R. 1966b: Scydmaeniden-Larven als Milbenräuber. Naturwissenschaften 53: 439-440.

Received February 2, 2016; revised and accepted April 19, 2016 Published online April 29, 2016 